\title{
A QUESTÃO DA CORRELAÇÃO DAS SUPERFÍCIES DE EROSÃO DO QUADRILÁTERO FERRÍFERO, MINAS GERAIS
}

\author{
CÉSAR A.C. VARAJAO*
}

\begin{abstract}
THE QUESTION OF THE QUADRILÁTERO FERRÍFERO EROSION SURFACES CORRELATION. Since the beginning of this Quadrilátero Ferrifero's geomorphological study, specially to the question of erosion surfaces and their correlation to this century many authors have dedicated themselves to the Brazilian southeastern planation surfaces. In this work the Quadrilátero Ferrífero's erosion surfaces were studied based in a morphometrical analysis, taking into consideration the number and surface área of the relief's high portions. The interpretation of quantitative analysis revealed that the erosion surfaces are the result of an important differential erosion process, and their articulation, of a significant lithostructural control. The regional correlation of erosion surfaces based in leveis is not recommendaded, due to lithological and structural diversities as well as to post Cretaceous tectonics.
\end{abstract}

Keywords: Morfometria, superfícies de erosão, Quadrilátero Fetrífero, Minas Gerais, Brasil.

RESUMO Desde o início deste século, vários autores se dedicaram ao estudo da geomorfologia do Quadrilátero Femfero, em especial à questão das superfícies de erosão e sua correlação com as superfícies de aplainamento da região sudeste do Brasil. Neste trabalho, as superfícies de erosão do Quadrilátero Femfero foram estudadas com base em uma análise morfométrica, levando-se em consideração o número de partes altas do relevo e suas respectivas áreas. A interpretação da análise quantitativa revelou que as superfícies de erosão resultam de um importante processo de erosão diferencial, e sua articulação, de um marcante controle estrutural. A correlação regional das superfícies de erosão fundamentada em níveis é temerária, pelas às diversidades litológicas, estruturais e à tectônica pós-cretácica.

Palavras-chaves: Morphometry, erosional surfaces, Quadrilátero Ferrífero, Minas Gerais, Brasil.

INTRODUÇÃO O Quadrilátero Ferrífero encontra-se localizado na parte central do Estado de Minas Gerais, abrangendo uma área de aproximadamente $7.200 \mathrm{~km}^{2}$. Trata-se de uma região montanhosa, dobrada, que constitui a extremidade sul do Cráton São Francisco (Alíiieida 1977).

A coluna estratigráfica dessa região foi primeiramente proposta por Harder \& Chamberlin (1915 a, b), modificada por Dorr (1969), posteriormente por Ladeira (1980) e recentemente por Alkimim et al. (1988). Geologicamente, é caracterizada por três grandes unidades litoestratigráficas:

- As rochas mais antigas da região são gnaisses e migmatitos, de idade arqueana, que constituem o embasamento cristalino para as unidades supracrustais;

- o Supergrupo Rio das Velhas constitui uma sequência arqueana tipo greenstone belt; $\mathrm{e}$

- o Supergrupo Minas é formado por espessos pacotes de rochas metassedimentares de idade proterozóica.

As rochas apresentam grau metamórfico na fácies xisto verde e o padrão grosseiramente quadrangular das serras que delimitam a região resulta de uma complexa história deformacional. Essas serras correspondem às abas dos anticlinais e sinclinais invertidos, constituídos por metassedimentos, e que, topograficamente, encontram-se fortemente realçados das terras baixas adjacentes, constituídas por gnaisses migmatíticos.

No decorrer da evolução do relevo do Quadrilátero Ferrífero, ocorreu a formação de pequenas superficies de erosão, que, distribuídas em diferentes altitudes e exibindo um nítido controle litoestrutural, constituem uma paisagem ímpar, quando comparada aos padrões da região Sudeste do Brasil. Os geomorfólogos que aí trabalharam procuraram, na maioria das vezes, efetuar correlações entre estas e as superfícies de aplainametno definidas no domínio da Plataforma Sulamericana (Tab. 1).
Neste trabalho, em $u$ ma primeira etapa, apresenta-se uma retrospectiva das principais contribuições sobre a ocorrência e distribuição das superfícies de aplainamento na região sudeste do Brasil e, em especial, no Quadrilátero Ferrífero.

Posteriormente, como subsídio à discussão sobre a evolução do relevo da região, efetua-se uma análise morfométrica, enfatizando a problemática da distribuição destas pequenas superfícies de erosão segundo níveis preferenciais, bem como a correlação destes com as superfícies de aplainamento.

A CARACTERIZAÇÃO DO RELEVO Contrastando geomorfologicamente com a paisagem monótona das colinas do embasamento, o Quadrilátero Ferrífero se caracteriza como uma área conspícua, apresentando exemplos didáticos de geomorfologia estrutural, erosão diferencial e superfícies de erosão.

O relevo atual foi determinando pela estrutura (Harder \& Chamberlin 1915 a, b, Tricart 1961, Barbosa \& Rodrigues 1964, 1965, 1967, Barbosa 1980) e pela erosão diferencial (Harder \& Chamberlin 1915 a, b, James 1933, De Martone 1943 a, b, Ruellan 1950, Freitas 1951, Tricart 1961, Barbosa \& Rodrigues 1964, 1965, 1967, Barbosa 1966, 1980, Dorr 1969).

A erosão diferencial se manifesta, nos grandes traços, por uma "coincidência" entre as ocorrências dos Grupos Caraça (quartzitos) e Itabira (itabiritos), e os relevos mais altos (Tricart 1961, Barbosa \& Rodrigues 1967). Quartzitos e itabiritos, mais resistentes, permaneceram como cristas, enquanto gnaisses migmatíticos, devido a sua menor resistência ao intemperismo e erosão, tornaram-se terras baixas (Harder \& Chamberlin $1915 \mathrm{a}, \mathrm{b})$. Xistos e filitos ocupam uma posição intermediária, e ocorrem, normalmente, preenchendo sinclinais e anticlinais topograficamente invertidos. Desse modo, o Quadrilátero Ferrífero constitui um mosaico formado por 
"províncias geomorfológicas" (Barbosa \& Rodrigues 1967) ligadas diretamente às condições estruturais. Nelas, variações na declividade das vertentes (Christofoletti \& Tavares 1976) e, sobretudo, variações altimétricas relacionam-se a variações litológicas.

As superficies de aplainamento No Quadrilátero Ferrífero, as superficies cimeiras encontram-se melhor preservadas, principalmente nas cristas que se desenvolve .: nas abas dos anticlinais e sinclinais, fato que levou muitos autores a interpretá-las como testemunhos de antigas superfícies de aplainamento. Nos níveis inferiores, os testemunhos são menos importantes em área, e a inferência de possíveis superfícies de aplainamento se dá por meio de planos horizontais imaginários, tangentes aos topos das colinas (somital surfaces).

Segundo Harder \& Chamberlin (1915 a, b), os topos aplainados das cristas constituiriam restos de um antigo peneplano de idade mesozóica e terciária inferior, que, após soerguido, sofreu intenso processo de erosão diferencial. Posteriormente, James (1933), De Martone (1943 a, b), Freitas (1951), Ab Saber (1954), King (1956), Barbosa \& Rodrigues (1965, 1967), Dorr (1969), Maxwell (1972), Lichte (1979) e Barbosa (1980) apresentaram contribuições à questão das superfícies de erosão no Quadrilátero Femfero, conforme sintetizado nas tabelas 1 e 2, cuja análise revela a existência de alguns pontos consensuais:

1. Primeiramente, constata-se uma unanimidade dos diferentes autores, exceto Brajnikok (1947), quanto à idade da superfície cimeira (ou dos Campos, ou Gondwânica etc.), que teria se desenvolvido no Cretáceo, sob condições de clima árido. Esta superfície é representada em extensas regiões do país por uma importante sedimentação continental correlativa.

Segundo os mesmos autores, após a geração da superfície cimeira, teria ocorrido o soerguimento da Plataforma Sulamericana, relacionado ao vulcanismo básico e à ruptura continental (Barbosa 1965, Braun 1971). Entretanto, existe diversidade de opiniões sobre a intensidade do soerguimento e sobre as superficies geradas posteriormente; por exemplo, a superfície Pós-Gondwânica de King (1956) não encontra correspondência com outros autores. Segundo Almeida (1951), Ab Saber (1954) e Barbosa (1965), a plataforma não teria se comportado como um bloco único durante o soerguimento, tratando-se, portanto, de um processo de epirogênese diferencial.
2. Abaixo dos testemunhos que restaram da superfície cimeira, encontra-se a superfície de maior expressão geográfica do sudeste do Brasil: a superficie das Cristas Médias, ou Paleogênica, ou Sulamericana. Trata-se de uma superfície imaginária, tangenciando o topo das colinas (somital surface), que teria sido gerada no Terciário Inferior. Não há concordância, entre os autores citados, sobre as condições climáticas deste intervalo de tempo e, ao contrário da superfície Gondwânica, faltam depósitos correlativos a este ciclo de erosão (Bigarella \& Ab Saber 1964, Braun 1971, Bigarela \& Becker 1975). 3. O terceiro ponto consensual refere-se à superfície Neogênica, ou Velhas, de idade plio-pleistocênica, formada sob condições de clima semi-árido, e que apresenta extensa sedimentação correlativa. É representada nas regiões costeiras pelo Grupo Barreiras (Bigarella 1975) e, no interior, especialmente acima do paralelo 20, por inúmeras formações terciárias correlacionadas ao tempo Barreiras (Schobbenhaus et al 1984).

Deve-se ressaltar, ainda, que, apesar das correlações possíveis entre as superfícies definidas pelos diferentes autores (Tab. 1), suas interpretações se fundamentam em modelos teóricos distintos.

No caso específico do Quadrilátero Ferrífero, a correlação entre as superficies de aplainamento perde o caráter consensual, principalmente no que se refere à correlação altímétrica (Tab. 2). Além disso, existem diferentes interpretações quanto ao número de níveis e quanto à correlação destes com as superfícies de aplainamento. Tal fato deve-se às diferentes interpretações morfogenéticas, uma vez que não se pode questionar a existência das superfícies de erosão. Barbosa (1980) alerta para o caráter local desses níveis, associados a variações litoestruturais, e constata a impossibilidade de correlacionálos regionalmente.

ANÁUSE MORFOMÉTRICA DO QUADRILÁTERO FERRÍFERO Objetivando o conhecimento quantitativo da altimetria do Quadrilátero Ferrífero, efetuou-se um estudo morfométrico utilizando-se mapas topográficos da região e levando-se em conta dois parâmetros: a. frequência das partes altas e, b. área das partes altas (Clarke 1966).

Coleta de dados A área estudada abrange cerca de quarenta folhas na - escala 1:25.000 (Convénio, DNPMUSGS/1946-1965), totalizando cerca de $7.190 \mathrm{~km}^{2}$ (Fig. 1).

Tabela 1 - Quadro das superficies de aplainamento na região SE do Brasil Table 1 - Situation of the planation surfaces in the southeast of Brazil

\begin{tabular}{|c|c|c|c|c|c|c|c|}
\hline \multicolumn{2}{|c|}{ IDADE } & $\begin{array}{c}\text { JAMES } \\
1933 \\
\end{array}$ & $\begin{array}{c}\text { DE MARTONE } \\
1943 \\
\end{array}$ & $\begin{array}{c}\text { FREITAS } \\
1951 \\
\end{array}$ & $\begin{array}{r}\text { KING } \\
1956 \\
\end{array}$ & $\begin{array}{c}\text { AB'SABER } \\
1964 \\
\end{array}$ & $\begin{array}{c}\text { BIGARELLA } \\
\text { \& } \\
\text { AB'SABER } 1964\end{array}$ \\
\hline \multirow{2}{*}{ 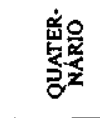 } & Holoceno & \multirow{6}{*}{$\begin{array}{l}\text { Planaltos } \\
\text { Cristalinos }\end{array}$} & \multirow{6}{*}{$\begin{array}{c}\text { Superficie } \\
\text { Neogênica } \\
\text { Superficie das } \\
\text { Cristas Médias } \\
\text { (Paleogênica) }\end{array}$} & \multirow{4}{*}{$3^{2}$ Ciclo } & \multirow{4}{*}{$\begin{array}{c}\text { Paraguaçu } \\
\text { Velhas }\end{array}$} & \multirow{6}{*}{$\begin{array}{c}\text { Superficie } \\
\text { Interplanáltica }\end{array}$} & \multirow{7}{*}{$\begin{array}{l}P_{d_{1}} \\
P_{d_{2}} \\
P_{d_{3}}\end{array}$} \\
\hline & Pleistoceno & & & & & & \\
\hline \multirow{5}{*}{ 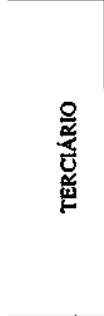 } & Plioceno & & & & & & \\
\hline & Mioceno & & & & & & \\
\hline & Oligoceno & & & \multirow{2}{*}{$\begin{array}{c}\text { Nível A } \\
\left(2^{2} \text { Ciclo }\right)\end{array}$} & \multirow{2}{*}{ Sulamericana } & & \\
\hline & Eoceno & & & & & & \\
\hline & Paleoceno & \multirow{4}{*}{$\begin{array}{c}\text { Cordilheira de } \\
\text { montanhas cristalinas }\end{array}$} & \multirow{4}{*}{$\begin{array}{c}\text { Superfície dos } \\
\text { Campos }\end{array}$} & \multirow{4}{*}{$\begin{array}{c}\text { Nivel B } \\
\left(1^{\circ} \text { Ciclo }\right)\end{array}$} & \multirow{4}{*}{ Pós-Gondwânica } & \multirow{4}{*}{$\begin{array}{l}\text { Superfície } \\
\text { cimeira }\end{array}$} & \\
\hline \multirow{3}{*}{ 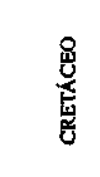 } & Superior & & & & & & \multirow{3}{*}{$\mathbf{P}_{d_{4}}$} \\
\hline & Médio & & & & & & \\
\hline & Inferior & & & & & & \\
\hline
\end{tabular}


Tabela 2 - Quadro das superficies de aplainamento no Quadrilátero Ferrífero, relacionando ciclos de erosão e níveis (m) TabJe 2 - The planation surfaces* situation in the Quadrilátero Ferrffero, relating erosion cycles and leveis (m)

\begin{tabular}{|c|c|c|c|c|c|c|}
\hline IDAD & AÜTORE & KING 1956 & $\begin{array}{c}\text { BARBOSAE } \\
\text { RODRIGUES } \\
1965,1967 \\
\end{array}$ & DORR 1969 & MAXWELL * 1972 & LICHTE * 1979 \\
\hline 番을 & Holoceno & & & & & \\
\hline 牽 & Pleistoceno & Paraguaçu & $\begin{array}{c}\text { Pediplano } \\
\text { PóśPliocênico }\end{array}$ & & & \\
\hline & Plioceno & $\begin{array}{c}\text { Velhas } \\
650\end{array}$ & $\begin{array}{c}\text { Pediplano } \\
\text { Pliocênico } \\
1.200\end{array}$ & $\begin{array}{c}\text { Velhas } \\
700-750\end{array}$ & $\begin{array}{c}V \\
700\end{array}$ & 900 \\
\hline$\frac{9}{3}$ & Mioceno & & & & & \\
\hline 送 & Oligoceno & Sulamaricana & & & & 1000 \\
\hline & Eoceno & 900 & & $850-900$ & 900 & 1,000 \\
\hline & Paleoceno & & & & & \\
\hline 8 & Superior & Pós-Gondwânica & & Pós-Gondwana & & 1.600 \\
\hline E & Médio & & & $1500-1650$ & II & \\
\hline 8 & Inferior & $\begin{array}{l}\text { Gondwânica } \\
1.500-1.600\end{array}$ & $\begin{array}{l}\text { Sup cimeira } \\
1.500-1.600\end{array}$ & $\begin{array}{l}1.750-1.850 \\
2.000-2.100\end{array}$ & I & $\begin{array}{l}1.800 \\
2.000\end{array}$ \\
\hline
\end{tabular}

* Dados referentes ao Distrito de Alegria

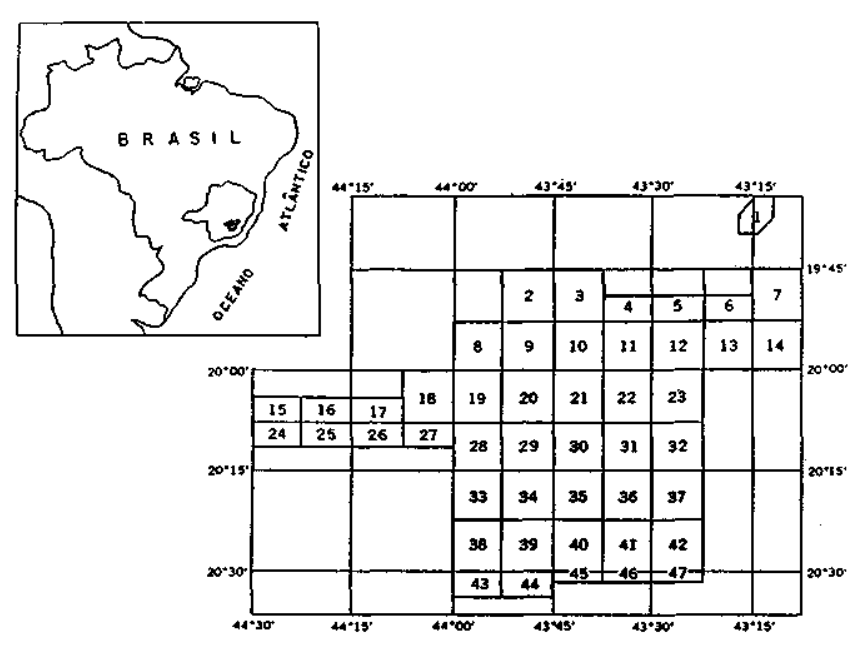

das, referentes a topos de colinas e platôs. Para o cálculo das áreas das partes altas, foi utilizada uma malha milimétrica, desenhada sobre papel ultraphan, que, uma vez colocada sobre uma curva de nível fechada, referente ao topo de uma elevação, possibilitava a contagem do número de milímetros quadrados contidos no interior da mesma.

Entre o valor mínimo de 600 e o máximo de $2.070 \mathrm{~m}$, foram contadas 7.457 partes altas, cujo somatório das áreas totalizou cerca de $605 \mathrm{~km}^{2}$, ou seja, 8,4\% da área estudada.

Quantificação do relevo As figuras 2 e 3 mostram, respectivamente, curvas de frequência de $\mathrm{N}$ (número de-partes altas) e A (soma das áreas das partes altas), em relação à altitude.

$\mathrm{Na}$ figura 2, observa-se que $\mathrm{N}$ mantém-se elevado entre 800 a $1.100 \mathrm{~m}$, apresenta uma queda acentuada entre 1.200 a $1.600 \mathrm{~m}$ e baixos valores entre 1.700 e $2.000 \mathrm{~m}$.

Na figura 3, repetem-se, a grosso modo, os três conjuntos presentes na figura 2, apesar da possibilidade de uma melhor identificação das modas. Entretanto, a importância do parâmetro A encontra maior expressão na figura 4 (curva de frequência $\mathrm{A} / \mathrm{N}$ ), na qual pode-se observar uma certa constância na frequência, entre 800 a $1.600 \mathrm{~m}$. Porém, a partir de $1.600 \mathrm{~m}$, apesar do pequeno número de ocorrência, as partes preservadas das superfícies cimeiras, associadas às litologias mais resistentes (quartzitos e/ou itabiritos), assumem grande expressão em área.

Como corolário, pode-se constatar que as maiores frequências de N (800 a $1.100 \mathrm{~m}$ ) relacionam-se, em verdade, a uma maior expressão em área de xistos, filitos e gnaisses migmatíticos, que, somados aos quartzitos e itabiritos, aos quais as superfícies cimeiras encontram-se associadas, constituem as rochas mais comuns da região.

Os níveis A figura 5, curva de frequência NxA, mostra que, por esse tipo de associação dos dados coletados, pode-se identificar um grande número de modas relativas a diferentes níveis. Entretanto, ao se variar os intervalos das classes (Fig. 6), percebe-se uma diminuição do número de níveis. Desse modo, pode-se constatar que o número de níveis é função da classe escolhida.

A coleta de dados de frequência das partes altas foi efetuada por meio da contagem dos valores das curvas de nível fecha- 


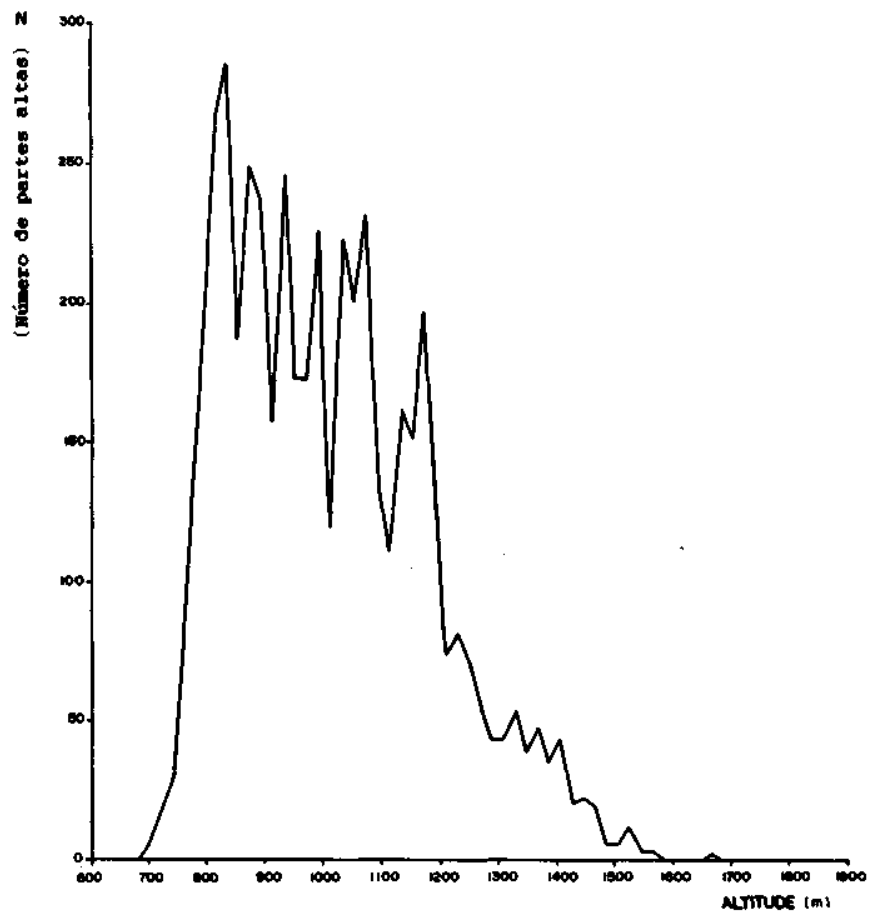

Figura 2 - Curva de frequência de $N$ (número de partes altas) do Quadrilátero Ferrífero, com intervalo de classe de $20 \mathrm{~m}$ Figure 2 - The Quadrilátero Ferrífero's frequency curve of N (number of high portions), with a class interval of $20 \mathrm{~m}$

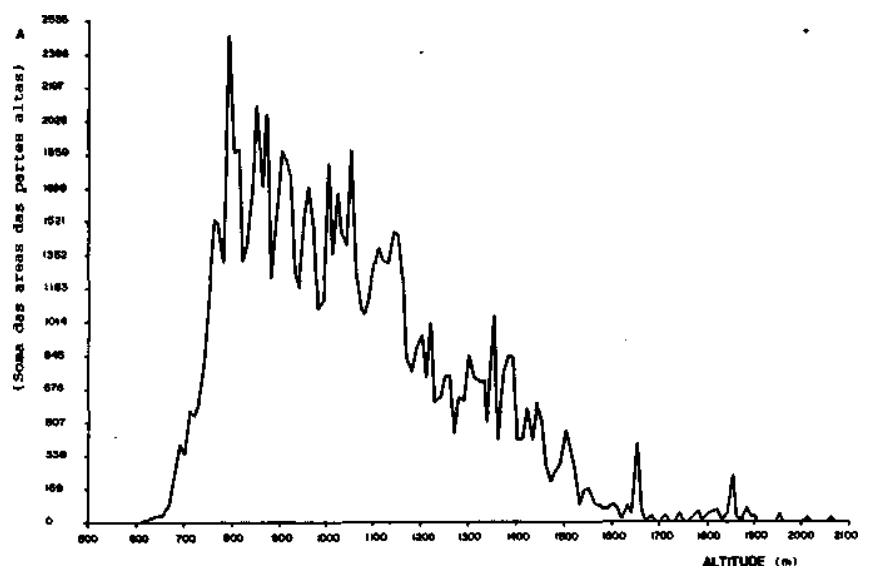

Figura 3 - Curva de frequência de A (soma das áreas das partes altas) do Quadrilátero Ferrifero, com intervalo de classe de $10 \mathrm{~m}$

Figure 3 - The Quadrilátero Ferrífero's frequency curve of A (addition of the high portions áreas), with a class interval of $10 \mathrm{~m}$

Tais fatos permitem aventar a hipótese de que os diferentes autores, quando da definição do número de níveis na região, trabalharam com intervalos de classe distintos, embora não tenham explicitado tal fato. King (1956), por exemplo, definiu superfícies de aplainamento da Plataforma Sulamericana, e procurou correlacionar as grandes feições do Quadrilátero Ferrífero às áreas adjacentes. Dorr (1969), por sua vez, ao abordar o Quadrilátero Ferrífero sem preocupar-se com as áreas adjacentes, sugeriu um número maior de níveis, enquanto Litche (1979), ao considerar apenas a porção nordeste do Quadrilátero Ferrífero, sugeriu um número ainda maior de níveis. Nesses termos, do ponto de vista quantitativo da análise morfométrica, seria possível supor que estes autores

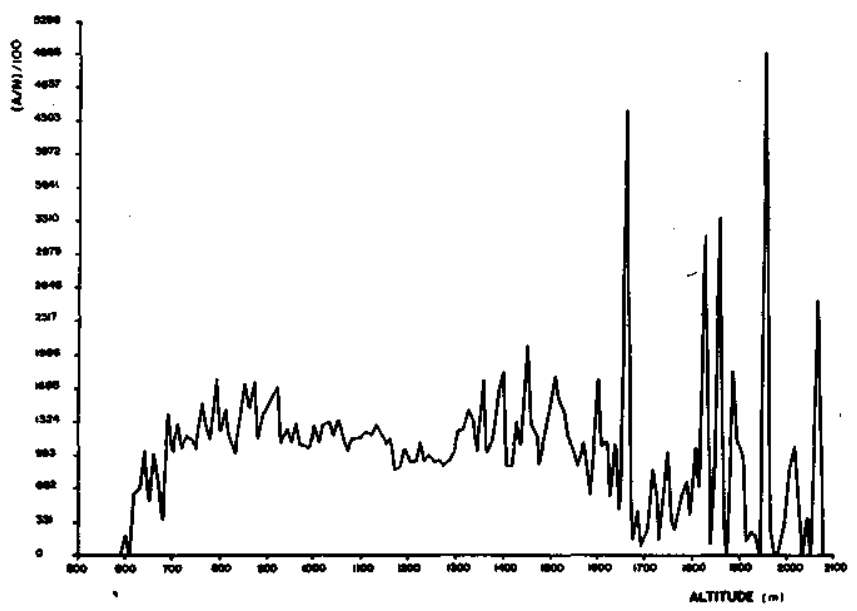

Figura 4 - Curva de frequência de A/N (soma das áreas das panes altas/número de partes altas) do Quadrilátero Ferrífero, com intervalo de classe de $10 \mathrm{~m}$

Figure 4 - The Quadrilátero Ferrífero's frequency curve of A/N (addition of the $h$ igh portions areas/number of $h$ igh portions), with a class interval of $10 \mathrm{~m}$

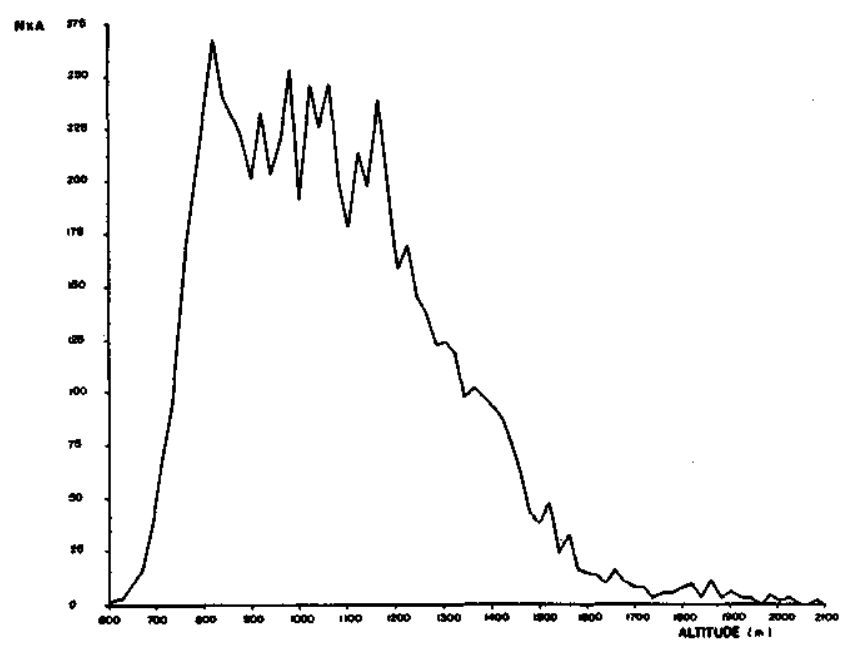

Figura 5 - Curva de frequência de Nx A (número de partes altas $x$ soma das áreas das partes altas) do Quadrilátero Ferrifero, com intervalo de classe de $10 \mathrm{~m}$ Figure 5 - The Quadrilátero Ferrífero's frequency curve of N x A (number of high portions $\mathrm{x}$ addition of the high portions áreas), with a class interval of $10 \mathrm{~m}$

trabalharam com intervalos de classe de 100, 50, e $20 \mathrm{~m}$, respectivamente.

O controle litoestrutural dos níveis A articulação dos níveis no Quadrilátero Ferrífero, intimamente relacionada a controles litológicos e/ou estruturais, encontra-se retratada na descrição das "províncias geomorfológicas" de Barbosa \& Rodrigues (1967).

A fim de melhor ilustrar a importância do controle litoestrutural sobre a articulação dos níveis na região, foi efetuada uma análise morfométrica setorial das áreas abrangidas pelas quadrículas Lopes Grande - Piedade do Paraopeba e Rio Acima - Gandarela (Fig. 1).

a. Análise morfométrica das quadrículas Lagoa Grande e Piedade do Paraopeba.

As figuras 7, 8 e 9 apresentam, respectivamente, as curvas de frequência de $\mathrm{N}, \mathrm{A}$ e $\mathrm{N}$ x A das quadrículas Lagoa Grande e Pieade do Paraopeda. Nessas figuras, é possível observar a existência de três níveis $(900-1.000,1.300-1.400$ e 1.500 $\mathrm{m})$, relacionados, respectivamente, ao Embasamento Cristalino (gnaisses migmatíticos), Grupo Piracicaba (filitos) e Gru- 


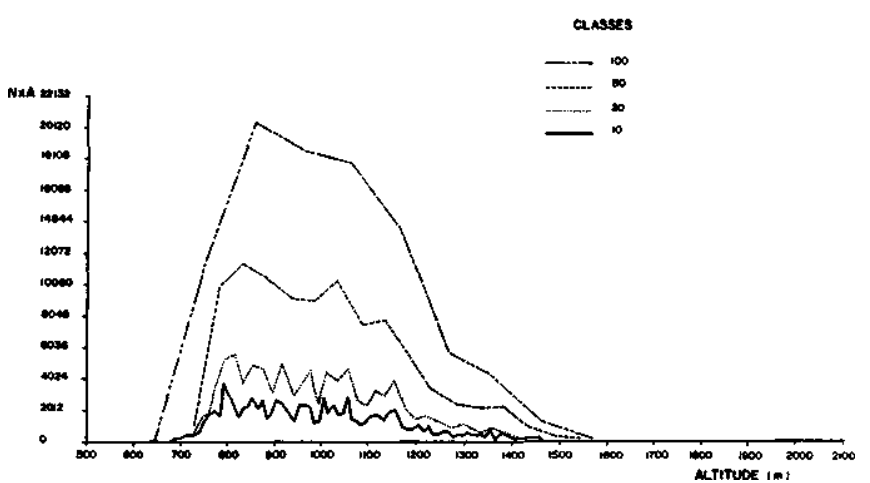

Figura 6 - Curvas ele frequência de $N$ x $A$ (número de parles altas x soma das áreas das partes altas) do Quadrilátero Ferrifero, com intervalos de classe de 10, 20, 50 e $100 \mathrm{~m}$

Figure 6 - The Quadrilátero Ferríferos frequency curves of $\mathrm{N} \times \mathrm{A}$ (number of high portions $\mathrm{x}$ addition of the high portions áreas), with class intervals of $10,20,50$ and $100 \mathrm{~m}$

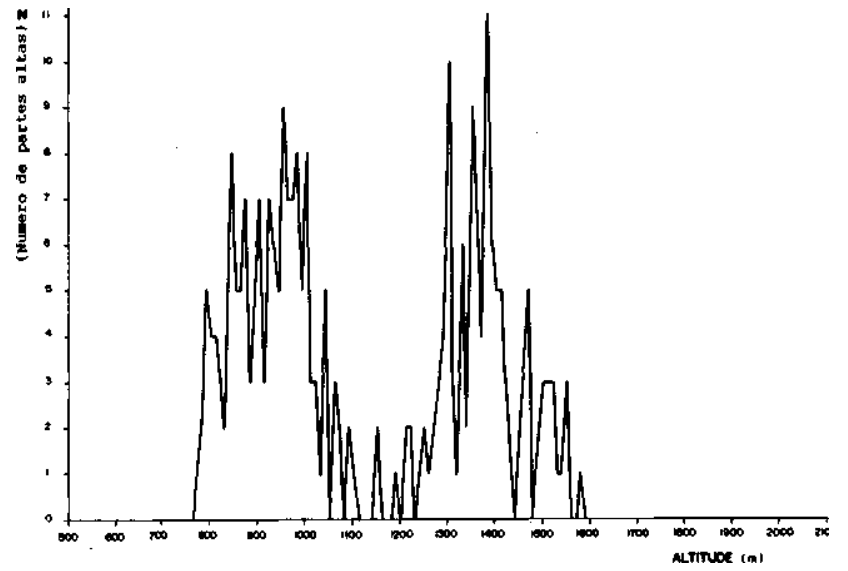

Figura 7 - Curva da frequência de $N$ (número de panes altas) das quadrículas Lagoa Grande e Piedade do Paraopeba, com intervalo de classe de $10 \mathrm{~m}$

Figure 7 - The Lagoa Grande and Piedade do Paraopeba quadrangles' frequency curve of $\mathrm{N}$ (number of high portions), with a class interval of $10 \mathrm{~m}$

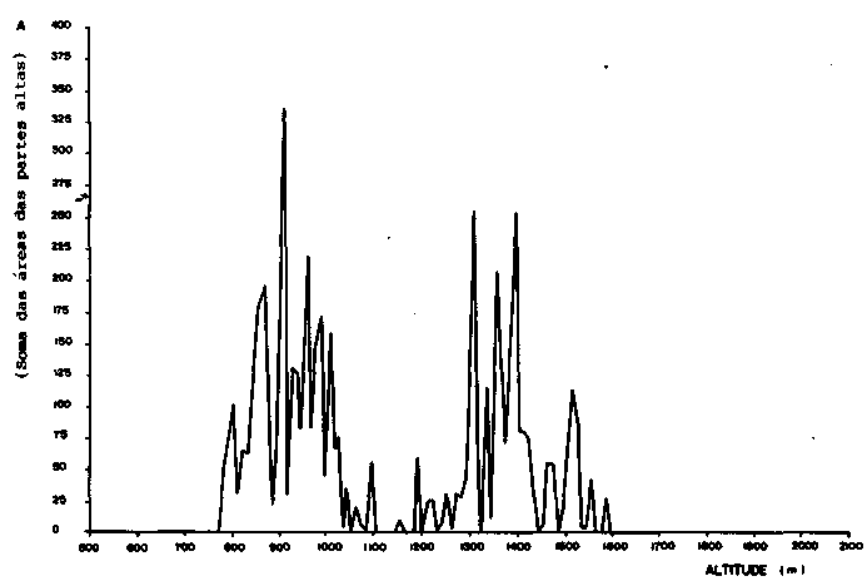

Figura 8 - Curva de frequência de A (soma das áreas das partes altas) das quadrículas Lagoa Grande e Piedade do Paraopeba, com intervalo de classe de $10 \mathrm{~m}$

Figure 8 - The Lagoa Grande and Piedade do Paraopeba quadrangles' frequency curve of A (addition of the high portions areas), with a class interval of $10 \mathrm{~m}$

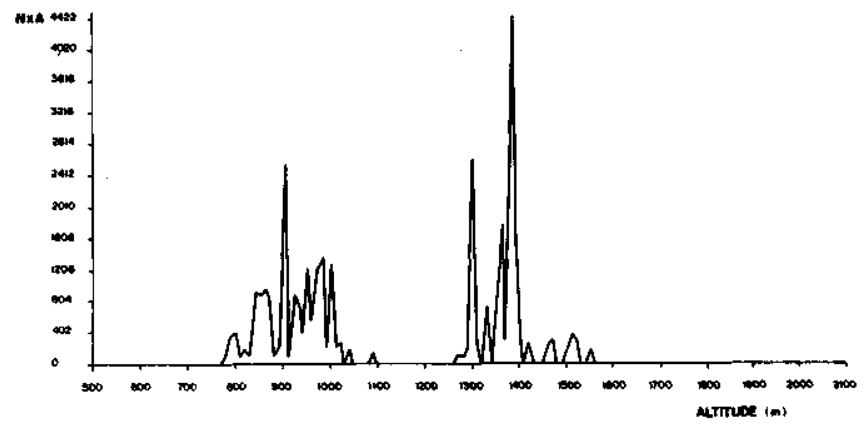

Figura 9 - Curva de frequência de $N \times$ A (número de panes altas $\mathrm{x}$ soma das áreas das partes altas) das quadrículas Lagoa Grande e Piedade do Paraopeba, com intervalo de classe de $10 \mathrm{~m}$

Figure 9 - The Lagoa Grande and Piedade do Paraopeba quadrangles' frequency curve of $\mathrm{N} x$ A (number of high portions $x$ addition of the higli portions áreas), with a class interval of $10 \mathrm{~m}$

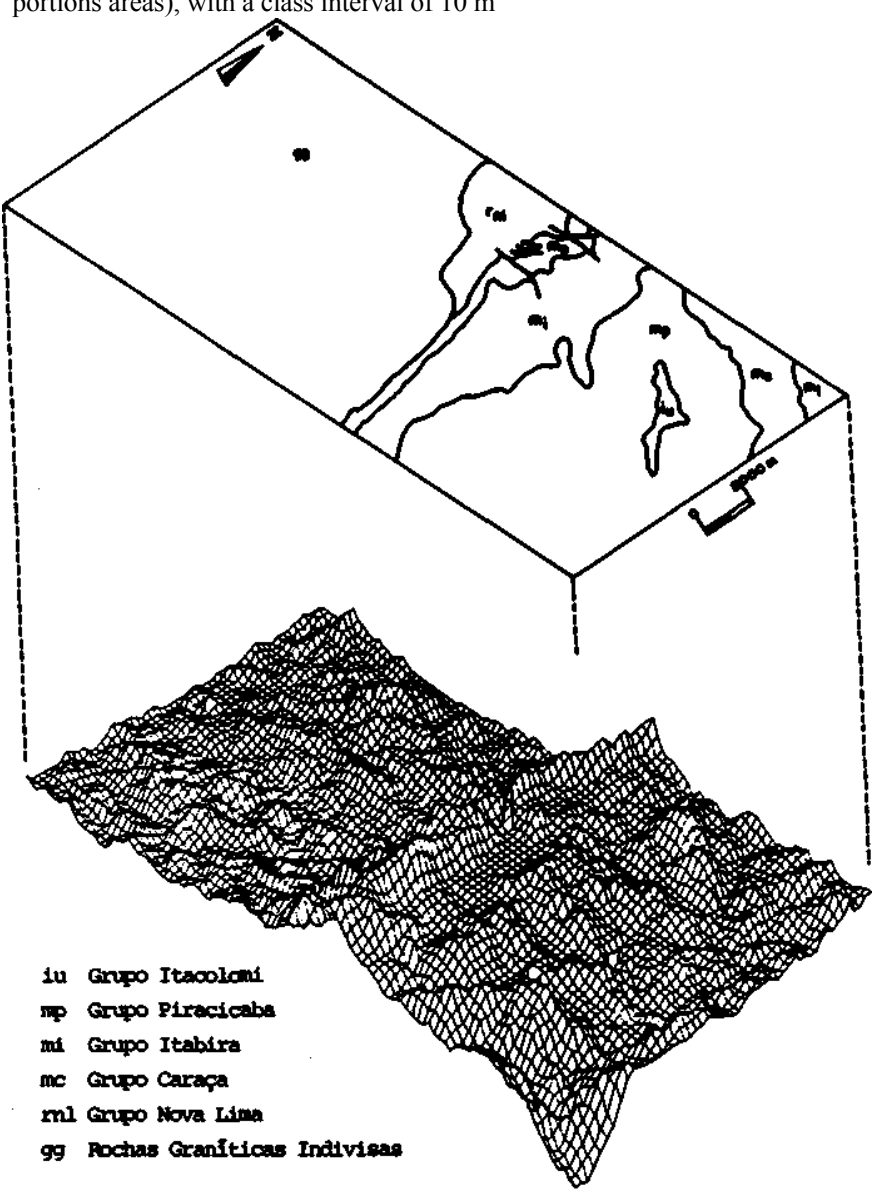

Flgura 10 - Bloco diagrama das quadriculas Lagoa Grande e Piedade do Paraopeba (geologia segwido Dorr 1969) Figure 10 - Diagram block of the Lagoa Grande and Piedade do Paraopeba ciuadraneles Ceeoloev bv Dorr 19691

po Itabira (itabiritos). A articulação e controle litoestrutural destes uiveis podem ser melhor observados no bloco diagrama da figura 10 .

b. Análise morfométrica das quadrículas Rio Acima e Gandarela.

As figuras 11,12 e 13 apresentam, respectivamente, curvas de frequência de N, A e N x A das quadrículas Rio Acima e Gandarela. Nestas figuras, é possível observar a existência 


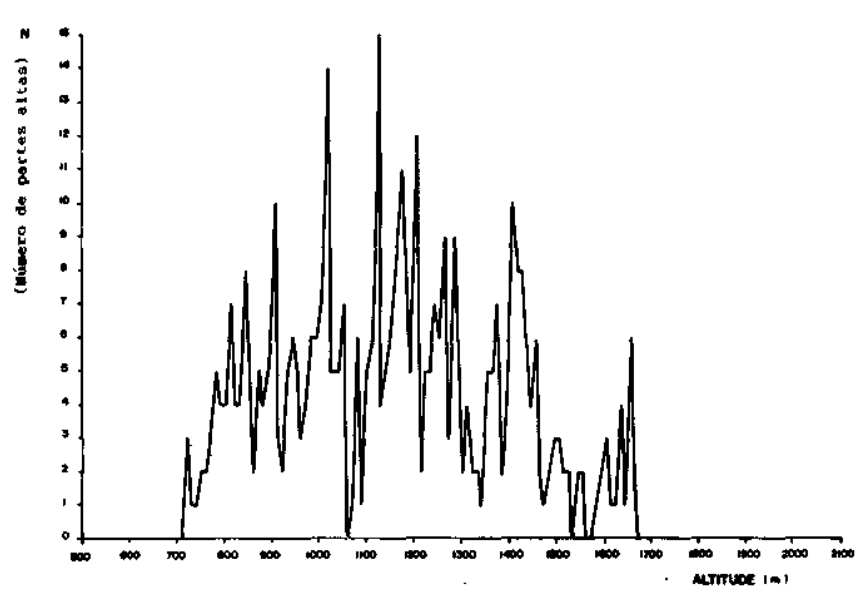

Figura 11 - Curva de frequência de $N$ (número de parles altas) das quadrículas Rio Acima e Gandarela, com intervalo de classe de $10 \mathrm{~m}$

Figure 11 - The Rio Acima and Gandarela's frequency curve of N (number of high portions), with a class interval of $10 \mathrm{~m}$

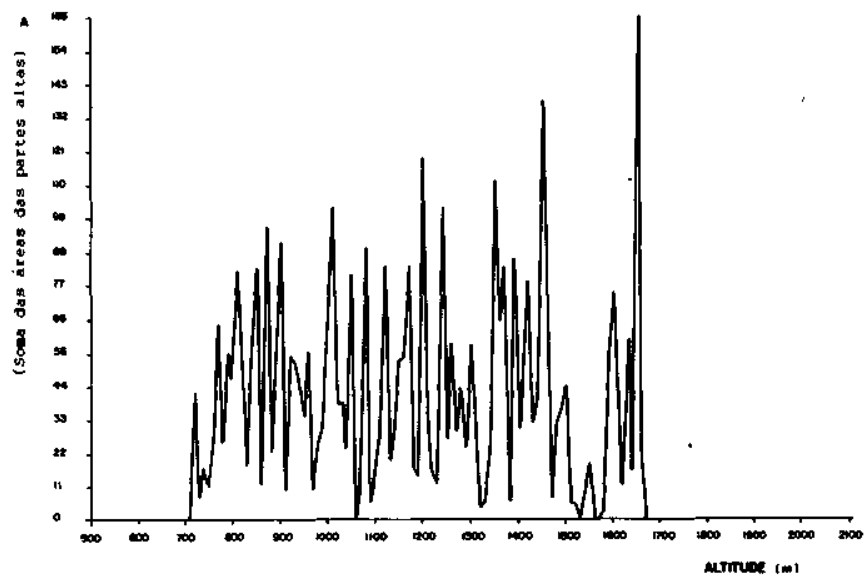

Figura 12 - Curva de frequência de A (soma das áreas das partes altas) das quadrículas Rio Acima e Gandarela, com intervalo de classe de $10 \mathrm{~m}$

Figure 12 - The Rio Acima and Gandarela's frequency curve of A (addition of the high porlions areas), with a class interval of $10 \mathrm{~m}$

de, pelo menos, seis níveis $(800$ - 900, 1.000, 1.100, 1.150 $1.250,1.350-1.450$ e $1.600-1.650 \mathrm{~m})$. Entretanto, as relações entre esses níveis e as variações litológicas não são tão claras como no exemplo anterior, conforme ilustra o bloco diagrama da figura 14. Tal fato se deve a variações litológicas internas nas unidades litoestratigráficas, que são caracterizadas por intercalações de quartzitos e quartzo xistos na área abrangida pelo Grupo Maquine. Esse fator, aliado à presença de falhamentos, provoca um acentuamento no escalonamento dos níveis. Além disso, o Grupo Itabira encontra-se aqui representado por suas duas formações, Cauê (itabiritos) e Gandarela (mármores dolomíticos), constituindo, respectivamente, a crista da aba NW do Sinclinal do Gandarela (Serras da Agua Limpa, Maquine e Lopes) e o relevo irregular, localizado no extremo leste da área.

\section{Os níveis e as superfícies de aplainamento}

exemplos descritos acima sugerem que a correlação das superfícies de erosão e a consequente definição de níveis, bem como a correlação destes com as superfícies de aplainamento, definidas na plataforma, devem ser analisadas com muita cautela. Ocorre que, nestas, a altimetria apresenta um caráter relativo, ao contrário dos termos absolutos da análise morfo-

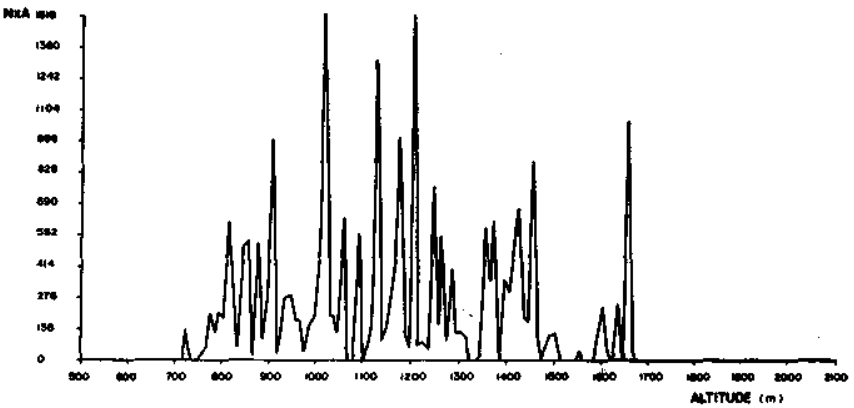

Figura 13 - Curva cie frequência de $N x A$ (número de partes altas x soma das áreas das partes altas) das quadrículas Rio Acima e Gandarela, com intervalo de classe de $10 \mathrm{~m}$ Figure 13 - The Rio Acima and Gandarela's frequeucy curve of N .x A (number of high portions $\mathrm{x}$ adiction of the high portions areas), with a class interval of $10 \mathrm{~m}$

métrica. Assim sendo, um determinado nível pode se referir a uma superfície de $1^{\mathrm{a}}, 2^{\mathrm{a}}$ ou $3^{\mathrm{a}}$ geração, dependendo da região considerada. Como exemplo, pode-se citar as abas do Sinclinal do Gandarela, onde o nível $1.150 \mathrm{~m}$, devido a um controle estrutural (Falha do Fundão), constituiria superfície de " 1 a geração" na aba NW e, de "3 ${ }^{\mathrm{a}}$ - ou $4^{\mathrm{a}}$ geração", na aba SE.

A análise morfométrica do Quadrilátero Ferrífero vem, portanto, confirmar a existência de uma estreita relação de dependência entre as pequenas superfícies de erosão existentes na região e as variações litoestruturais. Pela análise quantitativa, o aprimoramento dos conhecimentos relativos aos níveis do Quadrilátero Ferrífero permite afirmar que as tentativas de correlação das superfícies de erosão, objetivando a definição de níveis, é imprópria, bem como a correlação destes com superfícies de aplainamento definidas no domínio da plataforma. Tais conclusões são análogas às postuladas por Barbosa (1980), por intermédio de parâmetros distintos dos utilizados neste trabalho.

Diante de tais argumentações, coloca-se em cheque a questão da existência de ciclos de erosão que culminariam com a geração de superfícies de aplainamento de diferentes idades.

Numa tentativa de elucidar esta questão, com informações contidas em coberturas lateríticas, Varajão (1988) e Varajão et al. (1989) realizaram um estudo comparativo de 24 depósitos de bauxita existentes na região. Ao constatar que os depósitos se encontravam distribuídos entre 900 e $1.850 \mathrm{~m}$, e que apresentavam características texturais, químicas e mineralógicas semelhantes, estes autores concluíram que a bauxitização ocorreu no período Eoceno, quando o relevo jri apresentava uma compartimentação próxima da atual, corroborando, pois, com a hipótese da importância do controle litoestrutural na evolução da paisagem.

\section{A EVOLUC̃̃O MORFOGENÉTICA DO QUADRILÁTE-} RO FERRÍFERO Ao longo da evolução morfogenética do Quadrilátero Ferrífero, ocorreu uma conjunção especial das variáveis referidas anteriormente (estrutura, litologia, epirogêse e variações climáticas), de maneira a favorecer a formação de um relevo distinto do das áreas adjacentes. $\mathrm{O}$ diversificado conjunto litoestrutural da região foi submetido a variações climáticas e a atividade erosiva desde o Proterozóico, gerando um mosaico constituído por províncias geomorfológicas com nítido controle litoestrutural.

Os soerguimentos epirogenéticos pós-cretácicos, experimentados especialmente pela porção oriental da Plataforma Sulamericana, acarretaram, no Quadrilátero Ferrífero, o reentalhamento da drenagem e o rejuvenescimento do relevo, com fenómenos de captura associados. O realce das estruturas, através dos relevos invertidos, constituem um importante registro da evolução da paisagem. 


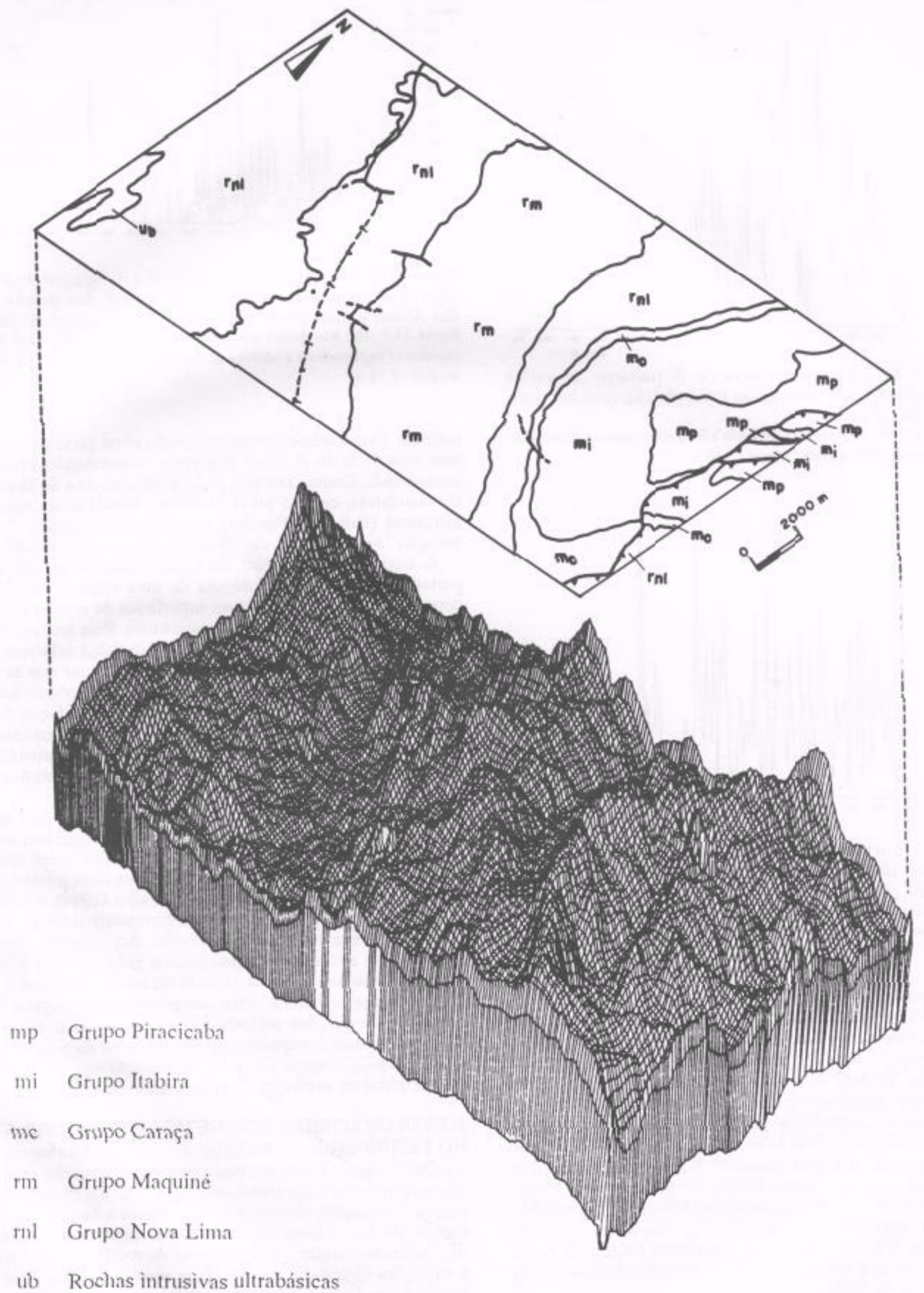

Figura 14 - Bloco diagrama das quadrículas Rio Acima e Gaudarela (geologia segundo Dorr 1969) Figure 14 - Diagram block of the Rio Acima and Gandarela quadrangles (geology by Dorr 1969)

Cabe ressaltar que, não obstante a estabilidade tectônica da região, por se situar no domínio do Cráton São Francisco, o Quadrilátero Ferrífero certamente foi afetado por soerguimentos epirogenéticos e falhamentos relacionados à tectônica 
distencional pós-cretácica. Tal fato encontra suporte na idade eocênica das bacias terciárias Gandarela e Fonseca (Lima \& Salard-Cheboldaeff 1981) e das bacias tafrogênicas da região Sudeste do Brasil (Melo et al 1985); bem como em evidências cinemáticas distensivas encontradas no Quadrilátero Ferrífero, em falhas de empurrão pré-cambrianas (Fernando Flexa Alkimim, comunicação verbal), constituindo, portanto, um complicador adicional para as tentativas de correlação entre níveis e superfícies de aplainamento.

CONCLUSÕES A análise global das contribuições sobre superfícies de aplainamento na região sudeste do Brasil e, particularmente, no Quadrilátero Ferrífero, revela um tema complexo, fundamentado em tópicos ainda não devidamente esclarecidos, tais como: condições paleoclimáticas, importância da tectônica pós-cretácica etc. Não obstante, a superfície da Plataforma Sulamericana, em sua longa evolução, desde o Paleozóico, adquiriu "cicatrizes", representadas por coberturas sedimentares e lateríticas, e eventos tectônicos e magmáticos que atestam esta evolução. Entretanto, as tentativas de correlações regionais, fundamentadas em dados altimétricos, revelam-se temerárias, dada a extensão da plataforma e as diversidades tectônicas, estruturais e litológicas, e a falta de um melhor conhecimento desses fatores.

No Quadrilátero Ferrífero, as cristas aplainadas, associadas a quartzitos e itabiritos, dominam, macromorfologicamente, as superfícies que tangenciam os topos das colinas (somital surfaces) associadas a xistos e filitos, que, normalmente, encontram-se preenchendo as calhas das estruturas com relevo invertido. Estas superfícies muitas vezes constituem superficies de erosão elevadas; entretanto, nestes casos, encontram-se claramente protegidas pelos "ombros" de quartzitos e/ou itabiritos. Finalmente, temos as somital surfaces associadas ao embasamento que, normalmente, constituem as superficies de erosão mais baixas do Quadrilátero Ferrífero.

Desta perspectiva, a evolução morfogenética do Quadrilátero Ferrífero revela um traço marcante de erosão diferencial que, ao longo do tempo, gerou pequenas superfícies de erosão, cuja articulação apresenta um nítido controle litoestrutural. Descarta-se, portanto, a possibilidade de correlações regionais das mesmas, bem como a existência de níveis correlacionáveis às superfícies de aplainamento definidas no domínio da plataforma.

Agradecimentos Gostaríamos de expressar nossos sinceros agradecimentos aos srs. Moacyr Godoy Jr. do Instituto Nacional de Pesquisas Espaciais (INPE) e Marcilio Andrade Pedrosa (LCC - DEGEO/DEMIN - Escola de Minas/UFOP) pelo auxílio na elaboração das figuras, e ao prof. dr. Fernando Flexa Alkimim (DEGEO/Escola de Minas/UFOP) pelas críticas e sugestões apresentadas para a melhoria do texto.

\section{REFERENCIAS BIBLIOGRÁFICAS}

AB'SABER, A.N. 1954. As altas superfícies de aplainamento do Brasil sudeste. Rev. Fac. Campineiras, 1(4):60-67.

ALKIMIM, ER; QUADE, H.; EVANGELISTA, M.T.R. 1988. Sobre a história da deformação dos metassedimeiitos do Supergrupo Minas e Grupo Itacolomi no Quadrilátero Ferrífero, Minas Gerais. Rev. Brás. Gcoc. (subm.)

ALMEIDA, F.F.M. 1951. A propósito dos "Relevos policíclicos na tectônica do escudo brasileiro". Boi. Paul. Geogr., 9:3-18.

ALMEIDA, F.F.M. J977. O Cráton São Francisco. Rev. Brás. Gcoc. 7(4):349-364.

BARBOSA, G.V. 1966. O significado da estrutura geológica para o mapeamento de Minas Gerais. Boi Min. Gcogr., 12:37-58.

BARBOSA, G.V. 1980. Superfícies de erosão no Quadrilátero Ferrífero, Minas Gerais. Rev. Bros. Gcoc., 10(1):89-101.

BARBOSA, G. $V . \&$ RODRIGUES, D.M.S. 1964. Apresentação e guia de excursão ao Quadrilátero Ferrifero. Belo Horizonte, FFCI/UFMG. 64 p.

BARBOSA, G. $V$ \& RODRIGUES, D.M.S. 1965. O Quadrilátero Ferrífero e seus problemas geomorfológicos. Boi. Min. Geogr., 10/11:3-35.

BARBOSA, G.V. \& RODRIGUES, D.M.S. 1967. Quadrilátero Ferrifero. Belo Horizonte, IG/UFMG. $130 \mathrm{p}$

BARBOSA, O. 1965. Quadro provisório de superfície de erosão e aplainamento no Brasil. Rev. Brás. Geogr., 27(4): 105-106.

BIGARELLA, J.J. 1975. The Barreiras Group in northeastern Brazil. An. Acad bras. Ciênc. 47(Supl.):365-393.

BIGARELLA. J.J \& AB'SABER, A.N. 1964. Palaogeographische und palãoklimntische Aspekte dês Kanozoikums in Südbrasilien. Z. Geomorpli., 8(3):286-312.

BIGARELLA. J.J. BECKER, R. 1975. Topics for cliscussion. Boi. Paran. Geoc. 33:170-276.

BRAJNIKO $V$, B. 1947. Essai sur Ia tectonique de Ia région a l' est de Belo Horizonte, Minas Gerais, Brésil. Buli. Soe. Geol. France, 27(5):321-335.

BRAUN, O.P.G. 1971. Contribuição à geomorfologia do Brasil central. Rev Bras. Geogr., 32(3):3-39.

CHRISTOFOLETTI, A \& TAVARES, A.C. 1976. Relação entre declividade de vertentes e litologia na área do Quadrilátero Ferrífero.. MG. Noí. Geomorfoi, 16(32):55-70.

CLARKE, J.I. 1966. Morphometry from niaps. In: DURY, G.H. ed. Essays in geomorphology. New York, Elsevier. p. 235-274.

DE MARTONE, E. 1943a. Problemas geomorfológicos do Brasil atlântico. Primeiro Artigo. Rev. Bras. Geogr., 5(4):3-30.

DE MARTONE, E. 1943b. Problemas morfológicos do Brasil atlântico. Segundo Artigo. Rev. Bras. Geogr., 6(2):3-26.

DORR, J.V.N. 1969. Physiographic, stratigraphicandstructuraldevelopment ofthe Quadrilátero Ferrifero, Minas Gerais, Brazil. Washington Geol. Survey Prof. Paper. 110 p. (641-A).
FREITAS, R.O. 1951. Relevos policíclicos na lectônica do Escudo Brasileiro. Boi. Paulista Geogr., 7:3-19.

IIARDER, E.C. \& CHAMBERLIN, R.T. 1915a. The geology of central Minas Geraes, Brazil. Part L Jour. Geol., 23(4):341-378.

IIARDER. E.C. \& CHAMBERLIN, R.T. 1915b. The geology of central Minas Geraes, Brazil. Part II. Jour. Geol., 23(5):385- 424

JAMES, P. 1933. The surfaces configuration of the southeastern Brazil. Anu. Ass. Am. Geogr., 23(3):165-193.

KING, L.C. 1956. A geomorfologia do Brasil oriental. Rev. Bras. Geogr., 18(2): 147-265.

LADEIRA, E.A. 1980. Met allogcnesis ofgold at the Morro Velho Mine in Nova Lima district, Quadrilátero Ferrífero, Minas Gerais, Brazil. London. 272 p. (Ph. D. Tliesis, University of West Ontario).

LICIITE, M. 1979. Morpliologie Untersuchung in der Serra do Caraça und ilirem Vorland Gõttigen. 139 p. D/5í. UniversitãtzuGõttigen. (Inédito).

LIMA, M.R. \& SALARD-CHEBOLDAEFF, M. 1981. Palynologie dês bassins de Gandarela et Fonseca (Eocène de Fétat de Minas Gerais). Boi IG-USP, 12:33-54.

MAXWELL, C.H. 1972. Geology and ore deposits of the Alegria district, Minas Gerais, Brazil. Washington, U.S. Geol. Survey Prof. Paper. 72 p. $(341-J)$

MELO, M.S.; RICCOMINI, C.; HASUI, Y.; ALMEIDA, F.F.M.; COIMBRA, A.M. 1985. Geologia e evolução do sistema de bacias tafrogênicas continentais do sudeste do Brasil. Rev. Bras. Geoc. 15(3): 193-201.

RUELLAN, F. 1950. Contribuição ao estudo da Serra do Caraça. An. Ass. Gcogr. Bras., 4(2):77-106.

SCHOBBENHAUS, C.; CAMPOS, D. A.; DERZE, G.R.; ASMUS, H.E. 1984. Geologia do Brasil. Texto explicativo do mapa geológico do Brasil e da área oceânica adjacente incluindo depósitos minerais. Brasília, MME-DNPM. $501 \mathrm{p}$

TRICART, J. 1961. Lê modele du Quadrilátero Ferrífero au sud de Belo Horizonte. Brésil. Anu. Geograpliie, 379:255-272.

VARAJÃ O, C.A.C. 1988. Estudo comparativo das jazidas de bauxita do Quadrilátero Ferrífero, MG. São Paulo. 232 p. (Dissertação de Mestrado, IG/USP).

VARAJÃO, C.A.C.: BOULANGÉ, B.; CARVALHO, A. 1989. The bauxites of Quadrilátero Ferrífero, Minas Gerais, Brazil. In: INTER. CONGR. OF ICSOBA, 6. Poços de Caldas, 1988. Proceeding... Travaux, ICSOBA, 19(22): 127-136. 